\title{
RANCANG BANGUN APLIKASI KOMUNITAS MANCING BERBASIS ANDROID
}

\author{
Edo Halim Saputra ${ }^{1}$, I Made Arsa Suyadnya ${ }^{2}$, I Made Oka Widyantara ${ }^{3}$ \\ Program Studi Teknik Elektro, Fakultas Teknik, Universitas Udayana \\ Email: edoliem92@gmail.com ${ }^{1}$, arsa.suyadnya@unud.ac.id ${ }^{2}$, oka.widyantara@unud.ac.id ${ }^{3}$
}

\begin{abstract}
ABSTRAK
Penelitian ini bermaksud untuk membangun sebuah aplikasi yang dapat menjadi wadah untuk para anggota komunitas mancing. Aplikasi dibangun berdasarkan tiga modul utama yaitu manajemen pengguna, manajemen spot mancing, dan manajemen diskusi. Aplikasi dibuat dengan menggunakan bahasa pemrograman java dengan platform android. Aplikasi ini juga memanfaatkan API (Application Programming Interface) yang dibangun dengan bahasa pemrograman PHP sebagai interface pengolahan data ke database. Pengujian aplikasi dilakukan dengan metode black box dan usability software, dengan hasil pengujian menyatakan bahwa tiga modul utama sudah berjalan dengan baik dan layak dipergunakan untuk menjadi sarana pertukaran informasi anggota komunitas mancing.
\end{abstract}

Kata Kunci : Android, Komunitas Mancing, Mancing

\section{ABSTRACT}

This research intends to build an application that can be a place for members of the fishing community. The application is built on three main modules: user management, spot fishing management, and discussion management. Applications built using java programming language with android platform this application also uses API (Application Programming Interface) built with PHP programming language as interface processing data to database. Application testing is done by black box method and usability software, with the test result stated that the three main modules are running well and deserve to be used to be a means of information exchange for members of the fishing community.

Keywords : Android, Fishing Community, Fishing

\section{PENDAHULUAN}

Kegiatan memancing bisa menjadi aktivitas pengisi waktu luang yang populer di masyarakat Indonesia dan peminatnya datang dari berbagai kalangan. Dengan banyaknya yang memiliki kesamaan minat dan hobi memancing, maka terbentuklah beberapa komunitas mancing di Indonesia.

Saat ini terdapat beberapa komunitas mancing di Indonesia, namun sampai saat ini belum terdapat komunitas online yang khusus membahas kegiatan mancing. Teknologi yang terus berkembang dapat dimanfaatkan oleh komunitas sebagai media untuk melakukan komunikasi dan saling bertukar informasi. Salah satu contoh pemanfaatan teknologi informasi adalah implementasi aplikasi pada perangkat mobile.
Saat ini, hampir setiap orang menggunakan handphone sebagai sarana komunikasi. Bukan hanya handphone dengan fasilitas dasar telepon dan SMS, melainkan berkembang pada perangkat smartphone. Berdasarkan data dari Statista [1], smartphone yang banyak digunakan adalah smartphone berbasis sistem operasi Android dengan persentase $60,71 \%$.

Banyaknya basis pengguna Android tersebut menjadikan perangkat mobile dapat dimanfaatkan sebagai sarana sebuah komunitas agar dapat berkomunikasi dengan cepat. Penelitian mengenai pengembangan aplikasi komunitas donor darah telah dibangun oleh Meilawati [2]. Aplikasi tersebut dapat memberikan informasi kebutuhan darah, solusi kasus dari anggota lain, dan informasi history daftar kasus kebutuhan darah. Penelitian yang dilakukan oleh Nuryuliani [3], 
merupakan penelitian yang membangun aplikasi yang memanfaatkan smartphone Android untuk pemberian informasi spasial dari sekolah-sekolah yang terdapat pada aplikasi. Dengan adanya informasi spasial ini, maka pengguna akan lebih mudah mengetahui informasi letak sekolah yang terdekat dari pengguna.

Sampai saat ini, belum terdapat komunitas online yang khusus membahas tentang kegiatan memancing. Jadi Dalam penelitian ini akan dibangun aplikasi komunitas mancing berbasis Android dengan menambahkan fitur-fitur yang akan mempermudah anggota komunitas mancing untuk saling bertukar informasi. Dalam aplikasi yang dibangun ditambahkan fitur layanan informasi geografis yang berfungsi untuk membagi lokasi spot mancing sebagai tempat yang baik untuk memancing.

\section{KAJIAN PUSTAKA \\ 2.1 Komunitas dan Forum}

Komunitas adalah sebuah kelompok sosial dari beberapa organisme yang berbagi lingkungan, umumnya memiliki ketertarikan yang sama. Dalam komunitas manusia, individu-individu di dalamnya dapat memiliki maksud, kepercayaan, sumber daya, preferensi, kebutuhan, risiko, kegemaran dan sejumlah kondisi lain yang serupa. [4]

Forum identik dengan diskusi. Diskusi sering dijadikan cara untuk bertukar pikiran dan membicarakan suatu permasalahan/topik secara bersama-sama lalu mencari solusi untuk kepentingan bersama pula. Sedangkan pengertian Forum Internet adalah sebuah papan pesan online (online bulletin board), tepatnya sebuah situs diskusi online di mana orang dapat memasukkan suatu topik dan memulai percakapan dalam bentuk pesan yang diposting. Ada juga yang menyebut sebagai "Komunitas Forum". Untuk bisa bergabung dalam pembahasan dan percakapan pada suatu forum, pengguna internet harus mendaftar (registrasi) terlebih dahulu. Biasanya, di situs forum akan ada sub-forum dengan beberapa topik berbeda. [4].

\subsection{Android}

Android adalah sebuah sistem informasi untuk perangkat mobile berbasis linux yang mencakup sistem operasi, middleware, dan aplikasi [5]. Android menyediakan platform yang terbuka bagi para pengembang untuk menciptakan aplikasi mereka. Perangkat Android merupakan perangkat yang memiliki satu layar foreground. Jadi, disaat pertama kali menghidupkan Android, layar akan berada di home. Apabila sebuah program dijalankan, User Interface-nya akan menumpuk di layar yang terbuka sebelumnya (home). Begitu juga apabila membuka menu 'play' yang merupakan bagian dari aplikasi tersebut, maka User Interface nya akan menimpa UI aplikasi tersebut dan seterusnya. Keseluruhan proses tersebut direkam di application stack oleh system activity manager. Tiap user interface diwakili oleh sebuah activity class. Tiap activity memiliki siklus seperti yang terlihat pada Gambar 1.

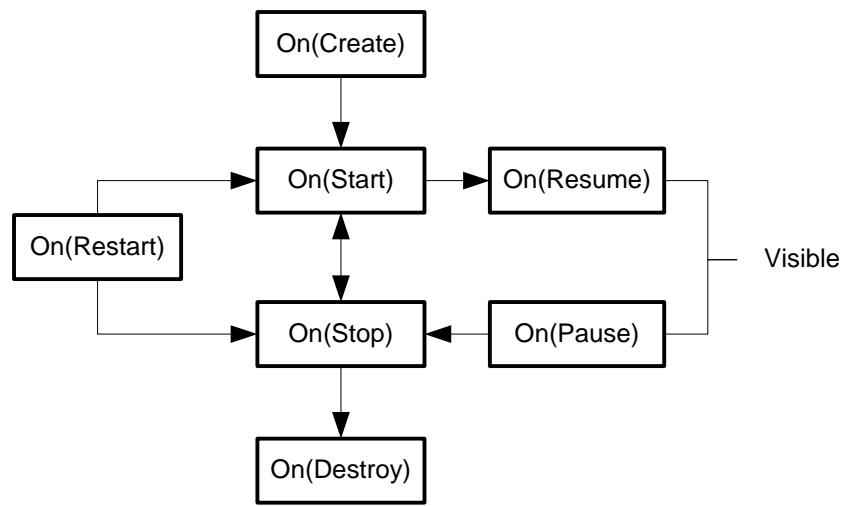

Gambar 1. Siklus Activity Android

Saat siklus berjalan secara otomatis siklus akan membuat stopped, paused, dan destroyed [5].

\subsection{Google Maps API}

API dapat dikatakan sebagai penghubung suatu aplikasi dengan aplikasi lainnya yang memungkinkan programmer menggunakan sistem function. Proses ini dikelola melalui operating system. Keunggulan dari API ini adalah memungkinkan suatu aplikasi dengan aplikasi lainnya dapat saling berhubungan dan berinteraksi. Bahasa pemrograman yang digunakan oleh Google Maps yang terdiri dari HTML, Javascript dan AJAX serta XML, memungkinkan untuk 
menampilkan peta Google Maps di website lain. Google menyediakan layanan Google Maps API yang memungkinkan para pengembang untuk mengintegrasikan Google Maps ke dalam website masingmasing dengan menambahkan data point sendiri. Dengan menggunakan Google Maps API, Google Maps dapat ditampilkan pada web site eksternal. Agar aplikasi Google Maps dapat muncul di website tertentu, diperlukan adanya API key. API key merupakan kode unik yang digenerasikan oleh google untuk suatu website tertentu, agar server Google Maps dapat mengenali [6].

\subsection{Basis Data}

Secara umum sistem basis data dapat didefinisikan sebagai koleksi dari data yang terorganisasi sedemikian rupa sehingga data mudah disimpan dan dimanipulasi. Manipulasi yang dimaksud yaitu diperbarui, dicari, diolah dengan perhitunganperhitungan tertentu, serta dihapus. Salah satu tujuan sistem basis data adalah menyediakan pengguna suatu pandangan abstrak dari data, yaitu sistem yang menyembunyikan rincian mengenai bagaimana data disimpan dan dipelihara, dimana agar sistem bermanfaat, pengguna sistem seharusnya dapat memanggil data secara efisien [7].

\section{METODE PENELITIAN}

\subsection{Tahapan Penelitian}

Langkah-langkah penelitian yang dilakukan untuk membangun aplikasi komunitas mancing berbasis android adalah sebagai berikut :

1. Melakukan analisis permasalahan dari aplikasi yang akan dibangun.

2. Melakukan studi literatur dengan mengumpulkan refrensi yang diperoleh dari buku-buku referensi serta modulmodul program dan tools yang dapat digunakan untuk membangun aplikasi ini.

3. Membuat pemodelan aplikasi yang akan digunakan dalam pembangunan aplikasi

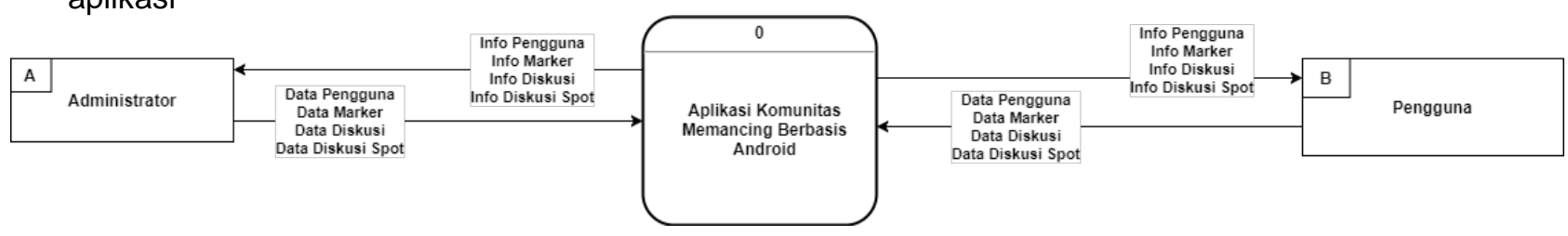

4. Perancangan basis data yang akan digunakan untuk menampung data yang diperlukan aplikasi

5. Melakukan uji coba, serta menganalisis aplikasi yang dibuat sehingga dapat berjalan dengan baik dan sesuai tujuan.

6. Memperoleh hasil dan kesimpulan dari aplikasi yang telah dibuat.

7. Pembuatan laporan berdasarkan cara penelitian yang dibuat.

\subsection{Gambaran Umum}

Perancangan aplikasi komunitas mancing berbasis android dapat dilihat pada Gambar 2 berikut ini.

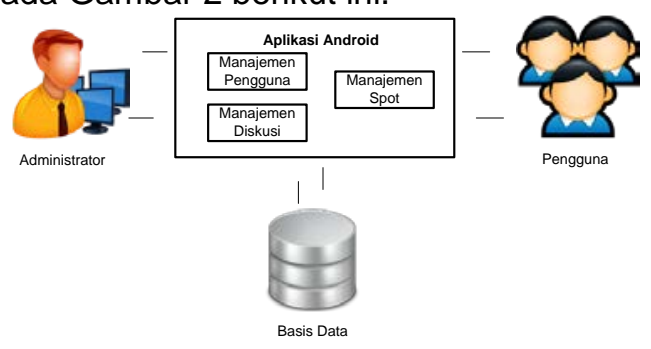

Gambar 2. Gambaran Umum Sistem

Aplikasi ini terdiri dari 3 modul utama, yaitu manajemen pengguna, manajemen spot mancing, dan manajemen diskusi. Aplikasi akan memiliki 2 aktor, yaitu administrator dan user. Administrator bertugas untuk mengelola user dan memverivikasi serta menghapus spot mancing dan diskusi thread yang ditambahkan oleh user. User memiliki hak untuk menambahkan spot mancing dan membuat diskusi thread baru.

\subsection{Pemodelan Sistem}

Pemodelan sistem akan dijelaskan Diagram).

\section{Diagram Konteks}

Diagram konteks dari aplikasi komunitas mancing yang akan dibangun dapat dilihat pada Gambar 3. dengan menggunakan DFD (Data Flow 
Gambar 3. Diagram Konteks

Aplikasi pada sistem ini memiliki 2 entitas dimana entitas yang pertama (admin) merupakan pengelola aplikasi komunitas mancing. Pada entitas kedua yaitu user merupakan anggota komunitas yang menggunakan aplikasi.

\section{DFD level 0}

Data flow diagram level 0 pada level ini dibagi menjadi 3 proses beserta entitasnya, yaitu proses manajemen user, spot, dan diskusi, seperti yang terlihat pada Gambar 4 berikut.

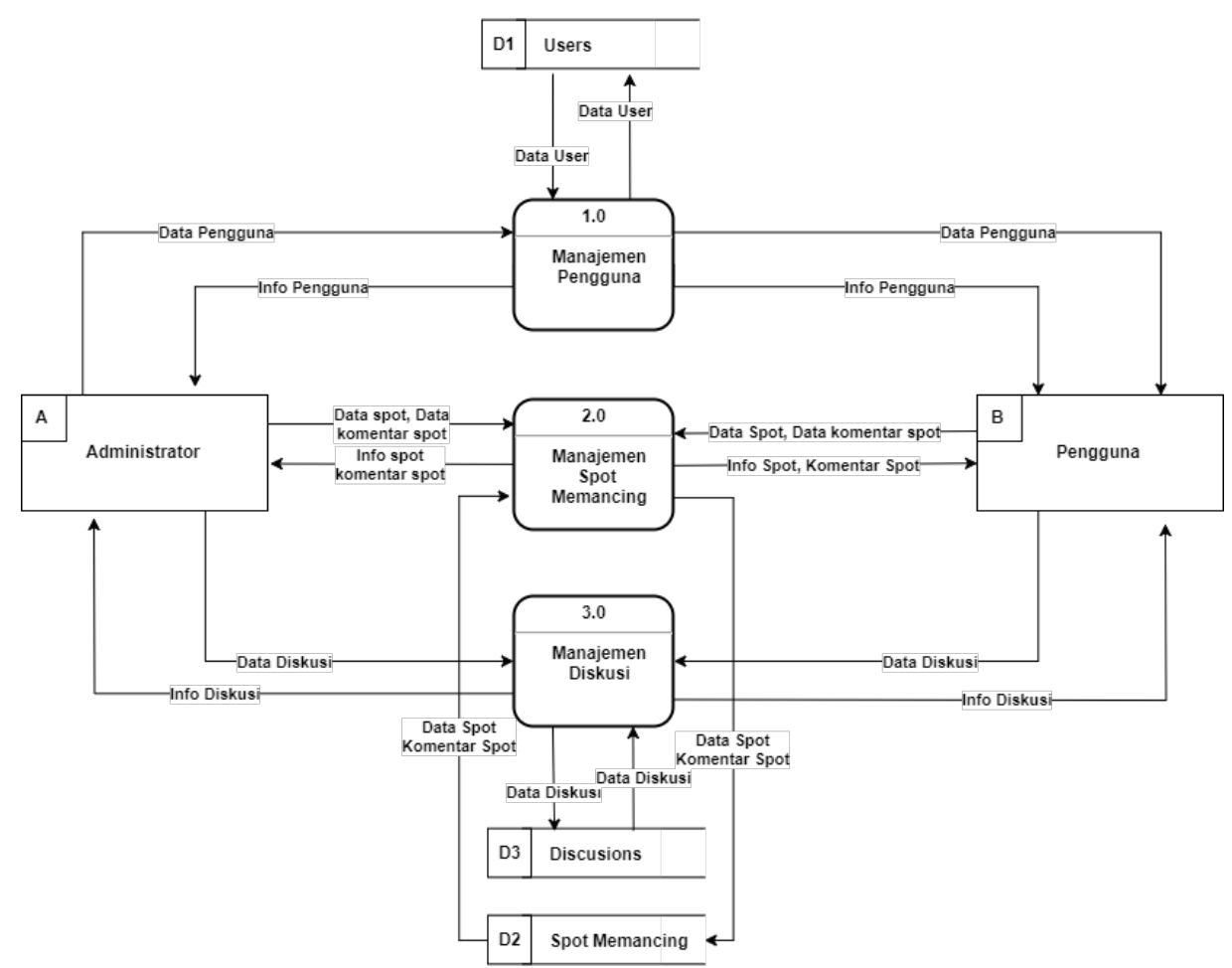

Gambar 4. DFD Level 0 Aplikasi Komunitas Mancing Berbasis Android

\subsection{Perancangan Database}

Aplikasi ini terdiri dari 6 tabel database yaitu tb_user, tb_spot_mancing, tb_rating, tb_komentar, tb_disscusions_thread, dan tb_disscusions_thread_detail.

Pada Gambar 5, dapat dilihat relasi antar tabel dari database.

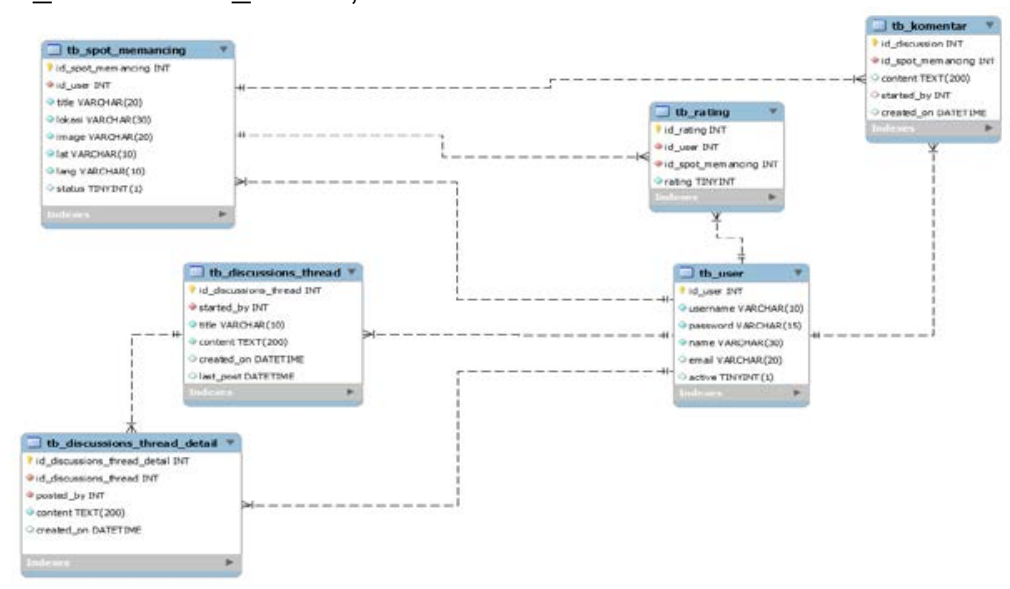


Gambar 5. Rancangan Database Aplikasi

\section{HASIL DAN PEMBAHASAN}

\subsection{Hasil Aplikasi}

Hasil dari penilitian "Rancang Bangun Aplikasi Komunitas Mancing Berbasis Android" ini adalah berupa aplikasi atau perangkat lunak yang dapat dijalankan via platform android. Aplikasi ini ditujukan untuk membantu dan memudahkan anggota komunitas mancing untuk saling bertukar informasi dan berbagi spot mancing.

\subsection{Pembahasan Aplikasi}

Pembahasan aplikasi akan dilakukan dengan menjelaskan seluruh fitur dari aplikasi.

\section{Halaman Home}

Setelah user melakukan login, maka user akan dibawa ke halaman ini. Fungsi dari halaman ini adalah agar pengguna dapat dengan mudah menuju halaman dan fitur yang disediakan pada aplikasi. Pada halaman ini akan tersedia tombol yang mewakili halaman dan fitur yang bersangkutan, pengguna akan menekan tombol tersebut untuk menuju halaman yang diinginkan. Halaman home dibedakan menjadi 2, yaitu halaman home untuk administrator dan halaman home untuk user biasa. yang membedakan halaman home administrator dan halaman home user biasa adalah pada hak aksesnya. User

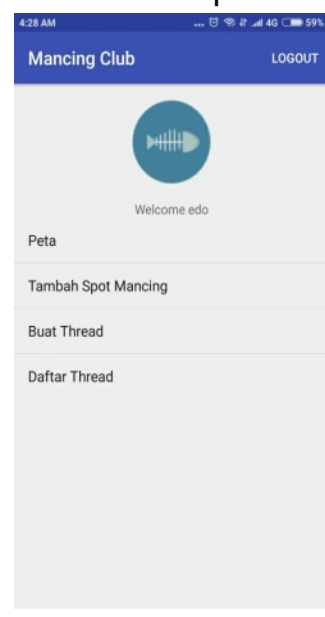

a)

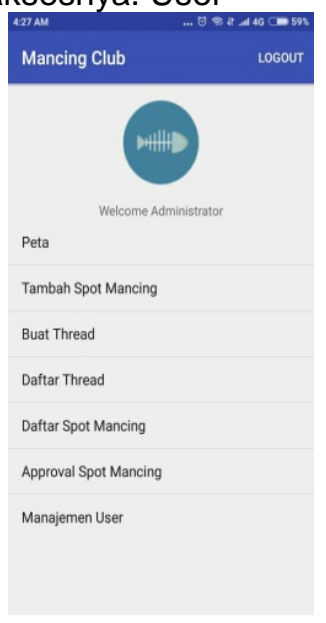

b) biasa hanya bisa mengakses 4 fitur utama, yaitu peta, tambah spot mancing, buat thread, dan daftar thread. Sedangkan untuk admin terdapat 3 fitur tambahan yaitu daftar spot mancing, approval spot mancing, dan manajemen user. Antarmuka halaman home dapat dilihat pada Gambar 6a dan $6 b$.

\section{Halaman Peta Spot Mancing dan Buat Spot Mancing}

Antarmuka peta spot memancing digunakan untuk menampilkan spot memancing yang dibuat oleh anggota komunitas dalam peta. Spot baru yang dimasukkan oleh user tidak langsung terlihat pada halaman ini, tetapi harus diapprove dahulu oleh administrator pada halaman approval spot memancing. Antarmuka buat spot memancing digunakan untuk dapat menambahkan marker. Untuk menambahkan spot baru, user harus menempatkan marker pada lokasi yang tepat di dalam peta, kemudian user diharuskan untuk mengisi nama spot dan lokasi spot, serta user juga diharuskan untuk mengupload gambar dari spot yang berkaitan dengan memilih menu upload. Kemudian user dapat menyimpan spot yang telah dibuat dengan menekan tombol simpan. Antarmuka halaman peta spot mancing dan buat spot mancing dapat dilihat pada Gambar 6c dan 6d.

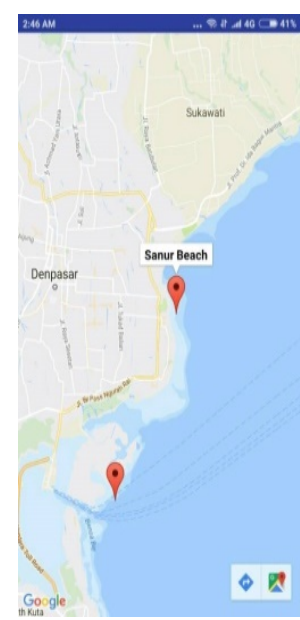

c)

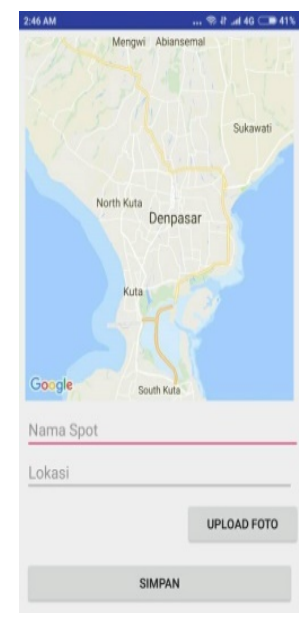

d) 
Gambar 6, a) Antarmuka halaman home sebagai user, b) Antarmuka halaman home sebagai administrator, c) Antarmuka peta spot mancing, d) Antarmuka buat spot mancing

\section{Halaman Diskusi Spot Mancing dan Posting Rating \\ Antarmuka diskusi spot memancing} digunakan untuk memberi komentar dan berdiskusi mengenai spot memancing yang ditandai dengan marker pada peta aplikasi. User dapat saling berdiskusi mengenai lokasi spot mancing terkait dengan cara menuliskan isi komentar pada kolom yang telah disediakan. User juga dapat memberi rating pada lokasi yang bersangkutan dengan cara menekan tombol beri rating. Antarmuka halaman diskusi spot dan posting rating dapat dilihat pada Gambar $7 \mathrm{a}$ dan $7 b$.

\section{Halaman Diskusi Thread, Daftar Diskusi Thread, dan Komentar Thread}

Halaman buat diskusi digunakan untuk anggota komunitas yang mana user dapat menambahkan thread atau diskusi. Untuk menambahkan thread, user harus menuliskan judul dari thread, serta menuliskan isi dari thread yang dibuat. Kemudian user dapat menyimpan thread yang telah dibuat dengan menekan tombol simpan. Buat diskusi digunakan agar anggota komunitas dapat berkomunikasi dan berdiskusi mengenai apapun yang tidak terkait dengan marker suatu spot memancing. Halaman daftar diskusi thread dapat diakses user ketika user memilih menu daftar thread pada halaman Home. Pada halaman ini akan terlihat daftar thread yang pernah dibuat oleh user lainnya. User dapat memilih salah satu dari thread ini dan dapat saling berdiskusi dengan user lainnya. Untuk memilih salah satu thread, user harus menekan kolom dari thread yang diinginkan. Antarmuka diskusi dan daftar diskusi thread dapat dilihat pada Gambar 7c dan 7d.

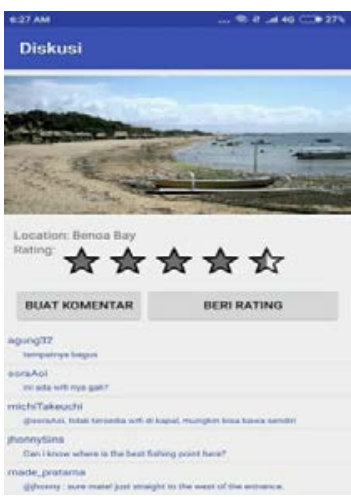

a)

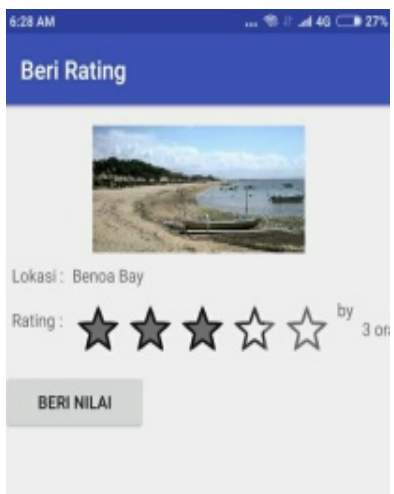

b)

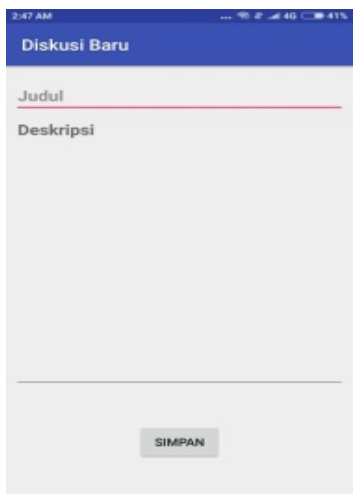

c)

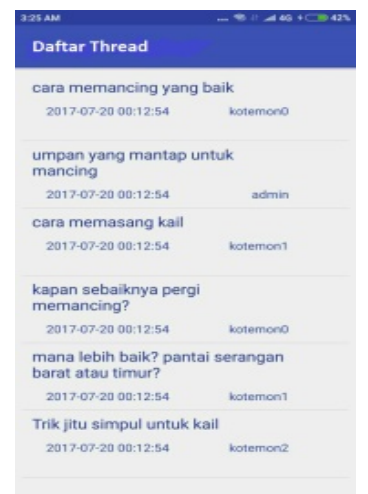

d)

Gambar 7, a) Antarmuka diskusi spot mancing, b) Antarmuka posting rating, c) Antarmuka diskusi thread, d) Antarmuka daftar diskusi thread

\section{Halaman Komentar Thread}

Antarmuka komentar thread digunakan untuk memberi komentar dan membalas diskusi atau thread yang telah dibuat sebelumnya oleh user lainnyaAntarmuka komentar thread dapat dilihat pada Gambar $8 a$.

\section{Halaman Manajemen User dan Manajemen Spot Mancing \\ Antarmuka manajemen user digunakan untuk administrator dalam}

mengelola user yang tergabung dalam aplikasi. Pada antarmuka ini, administrator dapat melihat detail informasi user selain password dengan menekan tombol detail. Selain itu, administrator juga dapat menekan tombol ban yang mana akan menghapus hak akses user tersebut. Antarmuka manajemen spot memancing digunakan untuk administrator dalam mengelola spot memancing yang tersedia dalam aplikasi. manajemen spot mancing, approval spot mancing, dan manajemen 


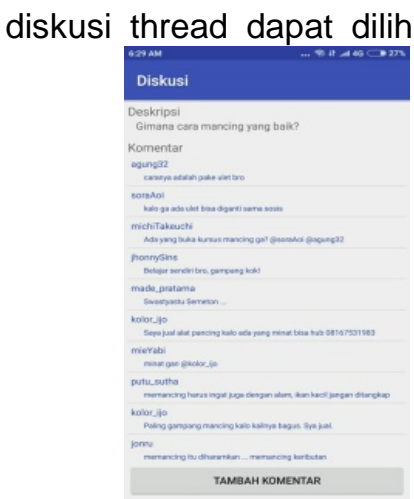

a)

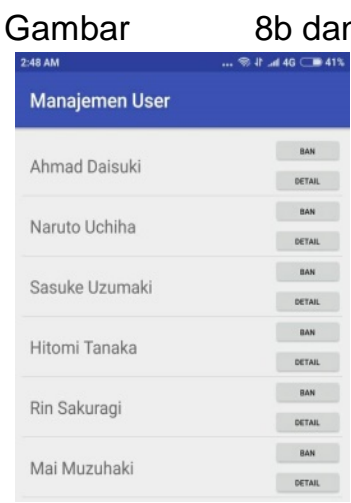

b)

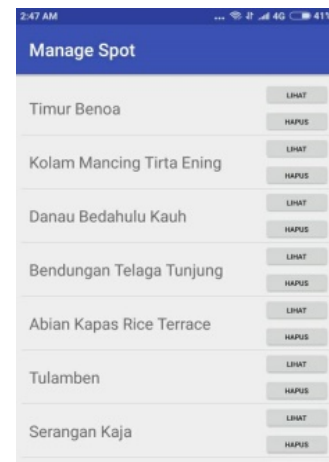

c)

Gambar 8, a) Komentar thread, b) Manajemen user, c) Manajemen spot mancing

\subsection{Pengujian Aplikasi}

Pengujian yang dilakukan pada aplikasi ini adalah pengujian blackbox dan usability software. Pengujian blackbox dilakukan untuk memperlihatkan bahwa fungsi-fungsi bekerja dengan baik. Dari keluaran yang dihasilkan, kemampuan program dalam memenuhi kebutuhan pemakai dapat diukur sekaligus dapat diiketahui kesalahan-kesalahannya. Pengujian dilakukan pada beberapa form menu dengan input atau kondisi tertentu.

Analisa usability software dilakukan dengan cara menyebarkan kuesioner dengan target responden adalah orang yang gemar melakukan kegiatan memancing. Jumlah responden untuk kuisioner ini sebanyak 10 orang, dimana pengguna akan mencoba untuk menjalankan fungsi-fungsi yang ada pada aplikasi ini. Hasil usability software menunjukkan 9 orang (90\%) mengatakan bahwa aplikasi ini sangat membantu dalam memudahkan user untuk saling berinteraksi dengan user lainnya, dan 1 orang (10\%) menyatakan aplikasi ini cukup membantu.

Berdasarkan hasil pengujian sistem dengan metode Blackbox dan usability software, didapatkan bahwa aplikasi komunitas mancing berbasis android sudah berjalan dengan baik dan layak dipergunakan untuk menjadi sarana pertukaran informasi anggota komunitas mancing.

\section{KESIMPULAN}

Proses perancangan kerangka dan alur sistem yang digambarkan lewat Data Flow Diagram (DFD) dan perancangan basis data lewat Physical Database Model (PDM) sudah sesuai dengan kebutuhan fungsional dari setiap level pengguna sistem.

Penelitian yang dilakukan berhasil menghasilkan aplikasi komunitas mancing yang sesuai dengan rancangan. Berdasarkan pengujian blackbox dan usability software dapat dinyatakan bahwa aplikasi berjalan dengan baik serta aplikasi layak digunakan sebagai media pertukaran informasi untuk anggota komunitas mancing.

Dari kesimpulan yang sudah didapatkan diatas, jika aplikasi akan berlanjut dikembangkan, saran yang dapat diberikan adalah agar ditambahkan teknik gamifikasi pada pengembangan aplikasi selanjutnya. Salah satu contohnya dengan menerapkan sistem poin pada fitur komentar.

\section{DAFTAR PUSTAKA}

[1] Statista, "• Mobile OS: market share in Indonesia 2012-2017 | Statistic," Market share held by mobile operating systems in Indonesia from January 2012 to July 2017, mei-2017. [Online]. Available:

https://www.statista.com/statistics/2622 05/market-share-held-by-mobileoperating-systems-in-indonesia/. [Accessed: 04-Sep-2017]. 
[2] K. Meilawati, R. Hendriyanto, and S. J. I. Ismail, Pembangunan Aplikasi Android Blood For Life dengan Menggunakan Arsitektur Rest Web Service. JTI, 2012.

[3] E. S. Mulyani, A. K Yapie, R. Kusuma, and others, "Aplikasi Location Based Service (LBS) Taman Mini Indonesia Indah (TMII) Berbasis Android," J. Fak. Huk. UII, 2013.

[4] Eva, "Kelebihan Forum Internet Online," Kelebihan Forum Internet Online. [Online]. Available: http://www.evadollzz.com/2014/10/abc d-\%20forum-internet-onlinekelebihan.html. [Accessed: 11-Jun2017].

[5] S. H. Nazruddin, "Pemrograman Aplikasi Mobile Smartphone dan Tablet PC Berbasis Android," Informatika, vol. 40, 2012.

[6] Y. Mufti, "Panduan Mudah Pengembangan Google Map Android," Yogyak. Andi, 2015.

[7] A. Nugroho, "Perancangan dan Implementasi sistem basis data," Yogyak. Andi, 2011. 